\title{
iff: tear
}

Revista de Educação, Ciência e Tecnologia

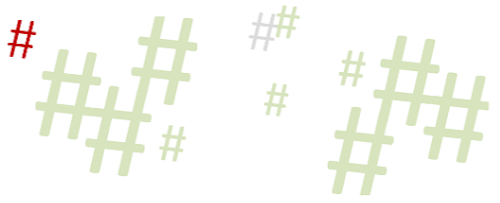

\section{A MEDIAÇÃO PEDAGÓGICA EM ESCOLAS DA PARAÍBA: O PAPEL DOCENTE NA CONSTRUÇÃO DO CONHECIMENTO ESCOLAR}

\author{
Pedagogical Mediation at Schools in Paraíba: The Teaching Role in the Construction of \\ School Knowledge
}

\author{
Mediación Pedagógica en las Escuelas de Paraíba: El Rol Docente en la Construcción \\ del Conocimiento Escolar
}

\author{
Aline dos Santos Pereira ${ }^{1}$ \\ Maria das Graças Almeida Baptista ${ }^{2}$
}

\begin{abstract}
Resumo: Esse artigo é fruto da dissertação de mestrado e trata do processo de mediação na construção do conhecimento escolar fundamentado na psicologia histórico-cultural. O objetivo é compreender a concepção do (a) professor (a) dos anos iniciais acerca do processo de mediação em escolas municipais de João Pessoa-PB. Em um primeiro momento, é apresentado o pensar vigotskiano acerca da construção do conhecimento na escola como a elevação das funções psíquicas superiores dos indivíduos a partir da mediação do adulto em sua relação com a criança. Assim, é necessária para que o sujeito, a criança, se aproprie de sua própria historicidade. Apresentam-se, com brevidade, algumas perspectivas pedagógicas atribuídas ao vocábulo mediação na modernidade, destacando os fundamentos teórico-metodológicos em Vigotski, ou seja, o desenvolvimento das funções psicológicas superiores e a formação dos conceitos na idade escolar. Para o desenvolvimento dessa pesquisa, optou-se por uma abordagem qualitativa, uma vez que ela parte dos significados sociais e subjetivos a ele relacionados. À guisa de considerações finais, constatou-se diferentes concepções acerca do processo de mediação que apontam uma dicotomia entre teoria e prática, o que corrobora a reprodução da divisão do trabalho manual e intelectual no meio da força de produção.
\end{abstract}

Palavras-chave: Mediação pedagógica. Concepção do mundo. Construção do conhecimento.

\begin{abstract}
This article is the result of a master's thesis and deals with the mediation process in the construction of school knowledge based on historical-cultural psychology. The objective is to understand the conception of the teacher in the early years about the mediation process in municipal schools in João Pessoa-PB. At first, we present Vygotskian thinking about the
\end{abstract}

\footnotetext{
${ }^{1}$ Mestre em Educação pela UFPB. Especialista em Educação em Direitos Humanos pela UFPB. Graduada em Pedagogia pela UFPB. Integra o Grupo de Estudos e Pesquisas em Filosofia e Psicologia da Educação- Ágora. Professora da Educação Básica no município de João Pessoa. ORCID: https://orcid.org/0000-0002-4795-4384. Email: aline.educ@outlook.com.

${ }^{2}$ Possui Pós-doutorado em Educação pela UNICAMP, Doutora e Mestre em Educação pela UFPB e Professora do Programa de Pós Graduação em Educação (PPGE/ UFPB). Líder do Grupo de Estudos e Pesquisas em Filosofia e Psicologia da Educação - Ágora. ORCID: https://orcid.org/0000-0003-1084-4269. Email: mgabaptista2@yahoo.com.br.
} 


\section{fid: tear}

Revista de Educação, Ciência e Tecnologia

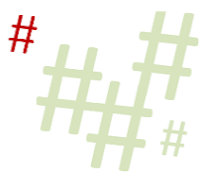

construction of knowledge at school as the elevation of higher psychic functions of individuals, from the mediation of the adult in their relationship with the child, it is necessary for the subject, the child, to appropriate of its own historicity. We briefly present some pedagogical perspectives attributed to the term mediation in modernity, highlighting the theoreticalmethodological foundations in Vygotsky, in other words, the development of higher psychological functions and the formation of concepts at school age. For the development of this research we chose the qualitative approach, since it starts from the social and subjective meanings related to it. With regard to the final considerations, we found different conceptions about the mediation process that point to a dichotomy between theory and practice, which corroborates the reproduction of the division of manual and intellectual labor in the middle of the production force.

Keywords: Pedagogical mediation. Conception of the world. Knowledge construction.

Resumen: Este artículo es el resultado de una tesis de maestría y trata sobre el proceso de mediación en la construcción del conocimiento escolar a partir de la psicología históricocultural. El objetivo es comprender la concepción del docente en los primeros años sobre el proceso de mediación en las escuelas municipales de João Pessoa-PB. En un primer momento, es presentado el pensamiento vigotskiano sobre la construcción del conocimiento en la escuela como la elevación de las funciones psíquicas superiores de los individuos a partir de la mediación del adulto en su relación con el niño. Por tanto, es necesario que el sujeto, el niño, se apropie de su propia historicidad. Presentamos brevemente algunas perspectivas pedagógicas atribuidas al término mediación en la modernidad, destacando los fundamentos teóricometodológicos en Vigotski, es decir, el desarrollo de funciones psicológicas superiores y la formación de conceptos en la edad escolar. Para el desarrollo de esta investigación se optó por un enfoque cualitativo, puesto que parte de los significados sociales y subjetivos relacionados con la misma. Como consideraciones finales, se encontraron diferentes concepciones sobre el proceso de mediación que apuntan una dicotomía entre teoría y práctica, que corrobora la reproducción de la división del trabajo manual e intelectual en la fuerza de producción.

Palabras clave: Mediación pedagógica. Concepción del mundo. Construcción de conocimiento.

\section{Introdução}

A escola, como espaço encarregado pela disseminação do conhecimento científico, deve compreender a construção de conhecimento vinculada à conjuntura social na qual está inserida. São os condicionantes econômicos, políticos e sociais que forjam os sujeitos e que, em sua totalidade, cercam a relação pedagógica, trazendo aspectos que podem ser relevantes para a construção do conhecimento sistematizado.

No tocante ao conhecimento científico, Vigotski ${ }^{3}$ (2009, p. 260) o apresenta como um conhecimento construído de forma elaborada, sistematizada. Dialeticamente, ele apresenta um outro conceito que, diferentemente do conhecimento científico, embora interligado a este, é

\footnotetext{
${ }^{3} \mathrm{O}$ nome do autor tem sido escrito de diferentes formas: Vygotsky, Vygotski e Vigotski. Em nossa pesquisa, utilizaremos a grafia Vigotski, utilizada no livro A construção do pensamento e da linguagem, 2. ed. São Paulo: Editora WMF Martins Fontes, 2009, com tradução de Paulo Bezerra. Nas indicações de referência, utilizaremos a grafia empregada em cada uma delas.

\# Tear: Revista de Educação Ciência e Tecnologia, v.10, n.2, 2021. 


\section{iff: tear}

Revista de Educação, Ciência e Tecnologia

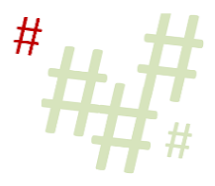

adquirido a partir da vivência do indivíduo com o meio em que se insere: o conhecimento espontâneo.

Por se constituir em sociedade, entendemos que para além de o homem ser um produto social, também é um ser histórico que se apropria de sua própria historicidade para se fazer um novo homem e, a partir dos conhecimentos construídos histórica e socialmente, transmite-os a outros sujeitos, transformando a realidade.

Fundamentado no materialismo histórico-dialético, Vigotski teoriza as relações que ocorrem no processo de ensino-aprendizagem e aborda como pressuposto a elevação das funções psíquicas superiores dos indivíduos a partir da mediação do adulto em sua relação com a criança. Para o autor, esse processo se constitui de forma lenta, dado que ocorre em estágios ontogenéticos e filogenéticos não lineares que estão condicionados às relações sociais e aos instrumentos de comunicação e às leis da biologia. São essas influências, juntamente com as atividades que serão desenvolvidas pelo indivíduo ao longo de sua trajetória que coordenam seu desenvolvimento e possibilitam a sua humanização e sua integração na sociedade.

Conforme salienta Duarte (1999, p. 26), "a formação do indivíduo é um duplo processo de relacionamento com o gênero humano, isto é, a apropriação das características humanas objetivadas e a objetivação individual mediada pelo que foi apropriado". Ao considerar o indivíduo como ser integral, ou seja, construído a partir da sua realidade, econômica, social e histórica, o(a) professor(a), sujeito responsável na escola pelo processo de inserção cultural do discente, contribui para a construção e a ampliação dos conhecimentos escolares, auxiliando-o nas objetivações genéricas para-si, ao mediatizar a relação entre o cotidiano e o não-cotidiano na formação desses alunos (as).

O pressuposto teórico que fundamenta o nosso entendimento do que é cotidiano e nãocotidiano é definido por Heller (1992, p. 17), ao definir que a vida cotidiana é aquela do "homem inteiro", "com todos aspectos de sua individualidade", embora seja inteiro, não tem "tempo, nem disponibilidade de se absorver inteiramente em nenhum desses aspectos" e isso independe de seu tempo histórico. Para a autora, a vida cotidiana é aquela em que o homem reproduz, mesmo que não seja um costume diário, atividades que são executadas sem reflexão e consciência quando estas se objetivam, ou seja, são atividades alienadas e, portanto, objetivações genéricas em-si.

Ao partir desse pressuposto, de que o cotidiano para Heller difere do sentido de dia a dia, compreendemos que nem toda atividade executada diariamente é uma atividade cotidiana e nem toda atividade que não é realizada diariamente faz parte do âmbito do não-cotidiano.

Considerando a teoria vigotskiana de que a aprendizagem ocorre antes do desenvolvimento, o(a) professor(a) deve fazer seu planejamento pedagógico de forma a expandir o conhecimento do(a) aluno(a) a partir de suas intervenções de forma a contribuir para a elevação cultural da criança e a sua humanização e, para que ocorra esse salto cultural, é imprescindível que o(a) aluno(a) haja diferentemente, ou seja, que sua ação não seja a mesma usada na cotidianidade.

\section{Mediação pedagógica na escola de Vigotski}

A palavra mediação, derivada do latim mediatio, entrou no dicionário de língua portuguesa em 1670, com o significado de intermediar pessoas ou um agrupamento de pessoas a fim de diminuir suas diferenças. 


\title{
iff: tear
}

Revista de Educação, Ciência e Tecnologia

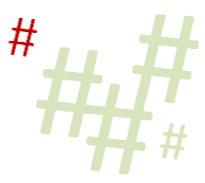

O significado de mediação varia de acordo com a especificidade de sua utilização. $\mathrm{Na}$ educação, o conceito de mediação, assim como outros conceitos, difere conforme a abordagem pedagógica e a linha teórica que a orienta.

No ensino a distância (EaD), o termo da mediação é recorrente. Nessa modalidade de ensino, o(a) professor(a) é o(a) facilitador(a) da mediação entre o(a) aluno(a) e o conhecimento apresentado na tela do computador, no qual, através de fóruns e chats, compartilham-se experiências, geram-se debates, afastando dúvidas e levantando questionamentos. Essa interação entre os(as) alunos(as), entre o(a) professor(a) e o próprio conhecimento apresentado é o processo mediador utilizado na $\mathrm{EaD}$.

Outra concepção de mediação pedagógica é o papel do(a) professor(a) que, com a comunicação e outros instrumentos necessários, realiza o seu fazer pedagógico, como uma ponte entre o(a) aluno(a) e o conhecimento.

\begin{abstract}
Um dos modos de conceber a educação como atividade mediadora é aquele em que a prática educativa escolar é entendida como um momento mais ou menos longo na vida do indivíduo (seus anos de escolarização), pelo qual passa a fim de adquirir as ferramentas culturais para sua atuação no meio social. A função de mediação da educação é concebida como "ponte" que liga dois pontos, uma mera passagem através da qual se atravessa uma determinada distância de um ponto ao outro. (OLIVEIRA; DUARTE, 1985, p. 95).
\end{abstract}

O conceito de mediação numa perspectiva materialista, conforme Cury (1986, p. 65), é visto na educação a partir de dois movimentos: o de camuflar ou o de desvelar a realidade das relações sociais. Portanto, o conhecimento pode assegurar a dominação de classe ou em seu movimento contraditório, conduzir a transformação social. É esse movimento contraditório da mediação como categoria analítica que nos ajudará a compreender as concepções das entrevistadas sobre o seu papel mediador em sala de aula e em como elas pensam esse processo.

Assumindo a perspectiva de mediação no processo educativo como uma relação do homem com o mundo e com seus pares, não sendo possível mensurar onde começa e termina a intervenção do homem no mundo e a influência do mundo no homem, tem-se um caráter de intencionalidade na educação, seja de transformação ou de reprodução das ideias dominantes.

Na condição de expoente da psicologia histórico-cultural, Vigotski começou a produzir sua teoria no fim de 1920 e início de 1930, enfrentando vários desafios teóricos e metodológicos na psicologia da então União Soviética (URSS). No que se refere à pedagogia, esse foi um período de transição do modelo czarista para uma fundamentação pedagógica de base socialista.

\footnotetext{
A teoria histórico-cultural, nos anos 20, deu início à pesquisa sobre a condição social da gênese da consciência do indivíduo. As pesquisas teóricas e experimentais levaram a um novo entendimento sobre a origem e a estrutura das funções psíquicas superiores, que se diferenciavam radicalmente da psicologia idealista dominante. As pesquisas mostraram que as funções psíquicas especificamente humanas, como o pensamento lógico, a memória consciente e a vontade, não se apresentam prontas ao nascer. Elas formam-se durante a vida como resultado da apreensão da experiência social acumulada pelas gerações precedentes, ao dominarem-se os recursos de comunicação e de produção intelectual (antes de mais nada, por meio da fala), que são elaborados e cultivados pela sociedade. (PRESTES, 2010, p. 36).
} 


\section{iff: tear}

Revista de Educação, Ciência e Tecnologia

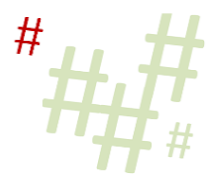

Os conceitos relacionados ao desenvolvimento do psiquismo, trabalhados na teoria vigotskiana trazem contribuições que são significativas para a educação, uma vez que apresentam algumas elucubrações sobre os processos de aprendizagem, a atividade consciente do homem e a apropriação dos conhecimentos historicamente acumulados, sendo esta última, segundo Duarte (1999, p. 92), "uma das características que distingue o ser humano dos animais, fazendo-o superior a todos os demais seres vivos por ter capacidade de acumular e transmitir experiência".

Em sua teoria, Vigotski buscou um novo enfoque ao interpretar a consciência como uma forma de organização do comportamento do homem, fundamentada nas suas experiências sociais, culturais e vivenciada em um determinado contexto histórico.

Essa breve apresentação histórica da conjuntura social e política na qual Vigotski estava inserido é imprescindível para que possamos compreender a influência materialista em sua teoria, visto que os fundamentos teóricos de Vigotski apontam para uma abordagem que busca compreender as relações do homem com e na sociedade, sendo essa relação situada historicamente e mediada por produtos e conhecimentos acumulados e transmitidos ao longo da história.

Vigotski não fundamenta seus estudos acerca da formação humana em um modelo epistemológico biológico, mas numa concepção histórico-social, na qual sujeito e objeto são históricos. Ele enfatiza que são as necessidades humanas e sua busca em satisfazê-las que transformam a natureza, a sociedade, o homem e os diferem dos animais. Assim, concordamos com Duarte (2003, p. 18), quando afirma ser contrário à afirmação de que a concepção vigotskiana é interacionista ou sociointeracionista.

Para analisar as relações entre a aprendizagem e o desenvolvimento da criança e fundamentar sua teoria acerca da essencialidade da transmissão do conhecimento historicamente acumulado, Vigotski trabalha com o conceito de Zona de Desenvolvimento Próximo (ZDP) e o Nível de Desenvolvimento Atual (NDA).

Conforme Martins e Duarte (2010, p. 111), a teoria desenvolvida por Vigotski compreende que o NDA, plano intrapsíquico, é fundamentado na ZDP, plano interpsíquico, tendo o(a) professor(a) como mediador(a) nesse processo de transformação.

O desenvolvimento de uma criança caracteriza-se por aquilo que ela já consegue fazer de forma independente e aquilo que ela consegue fazer com a ajuda de outras pessoas - e aqui sinalizamos que cada criança tem um potencial de aprendizagem, independentemente de sua idade biológica, sendo assim, o desenvolvimento mental de uma criança vai se constituindo a partir do NDA e a ZDP.

Trabalhar a partir daquilo que a criança ainda não tem conhecimento, de forma que possa vir a realizar sozinho, é operar na ZDP, ou seja, é nessa fase de desenvolvimento em que as funções psíquicas superiores estão se desenvolvendo, em que se situa o papel determinante do adulto ou de uma criança mais velha. Na escola, esse papel é exercido pelo(a) professor(a).

Os conhecimentos que a criança já realiza sem o auxílio de um(a) adulto(a), representam o NDA e para ativar o desenvolvimento das funções psíquicas da criança é preciso atuar na ZDP, para que aquilo que antes a criança não sabia fazer sozinha passe a fazer, entrando em um outro NDA e assim se construa outras ZDPs. O que hoje é ZDP, amanhã pode vir-a-ser NDA, através da mediação do(a) professor(a) em sua relação com o(a) aluno(a). 


\title{
iff: tear
}

Revista de Educação, Ciência e Tecnologia
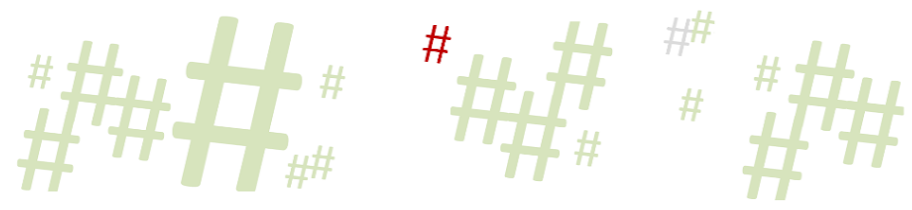

\begin{abstract}
A ZDP refere-se aos processos que a criança consegue realizar apenas em colaboração com outros, na atividade coletiva, ou seja, que só podem efetivar-se no plano interpsíquico. O que a criança é capaz de fazer hoje no plano interpsíquico, conseguirá fazer amanhã com autonomia, no plano intrapsíquico, como conquista de seu desenvolvimento psíquico individual. Com o conceito de ZDP, segundo Vigotski (1995), altera-se profundamente a concepção sobre as relações entre educação e desenvolvimento. Tradicionalmente, observa-se a preocupação em se adaptar a educação ao desenvolvimento, respeitando os prazos, o ritmo, as características do pensamento e da percepção infantis. (MARTINS; DUARTE, 2010, p.173).
\end{abstract}

O desenvolvimento da aprendizagem e a construção de conhecimento no ser humano, conforme a perspectiva vigotskiana, ocorre de forma não linear, mas dialética. Ou seja, o que hoje a criança não compreende, pode compreender amanhã e a partir dessa compreensão, outras dúvidas podem ser desencadeadas e, ao serem estimuladas, passam a ser conhecimento. Assim, não há limite para o desenvolvimento das funções psíquicas humanas quando elas são instigadas.

A partir dessa compreensão sobre como ocorre o desenvolvimento, o processo de aprendizagem dos(as) alunos(as) em sala pode começar com uma observação acerca daquilo que o(a) aluno(a) pode fazer de forma autônoma para, em seguida, ocorrer de forma intencional a mediação docente, visando alcançar a ZDP e, assim, ensinar a criança aquilo que ela não conseguiria aprender sozinha, mas que é possível por intermédio dos conhecimentos acumulados pelo homem e em colaboração com o(a) professor(a).

A elevação da vida cotidiana ocorre quando o conhecimento não se define na relativização do cotidiano, quando se é capaz de produzir e transformar as práticas sociais, ou seja, à medida que irrompe a consciência nas relações sociais e o pragmatismo cede espaço para a reflexão, quando não há separação entre o ser e a essência, quando o homem se apropria das objetivações genéricas para-si.

\begin{abstract}
A atividade prática do indivíduo só se eleva ao nível da práxis quando é atividade humano-genérica consciente; na unidade viva e muda de particularidade $\mathrm{e}$ genericidade, ou seja, na cotidianidade, a atividade individual não é mais do que uma parte da práxis, da ação total da humanidade que, construindo a partir do dado, produz algo novo, sem com isso transformar em novo o já dado (HELLER, 1992, p. 32, grifos da autora).
\end{abstract}

Apropriar-se das objetivações genéricas para-si é não se restringir à reprodução do indivíduo, mas também reproduzir a realidade sócio-histórica construída pelo homem através da cultura e das ciências, relacionando-se conscientemente com sua vida cotidiana a partir de ações não-cotidianas.

Trabalhar a teoria do cotidiano de Heller e a psicologia histórico-cultural na educação escolar é compreender que o fazer pedagógico não se reduz às atividades cotidianas da realidade escolar, mas faz parte de uma ação mediadora da formação do(a) aluno(a) com sua cotidianidade e as relações que podem ser trabalhadas a partir da consciência e da reflexão do que não está aparente. É a partir da mediação do cotidiano com o não-cotidiano, da apropriação das objetivações históricas produzidas pelo homem, que o fazer pedagógico e a aprendizagem podem superar a aparência e iniciar uma jornada para a essência das coisas situadas na prática social humana. 


\section{iff: tear}

Revista de Educação, Ciência e Tecnologia
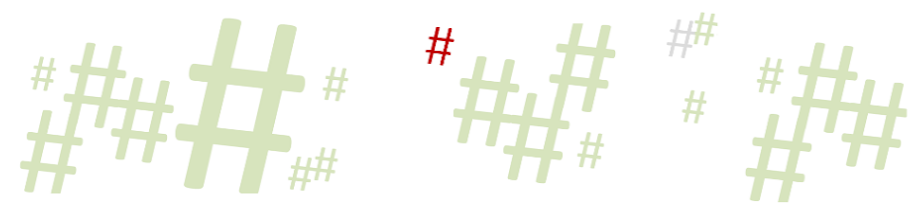

Seria, portanto, um equívoco de nossa parte pretender que a educação escolar tivesse o poder de superar a alienação, enquanto processo objetivo-social enraizado nas relações de produção. Mas também entendemos que cabe a educação escolar um papel bastante significativo na luta pela transformação dessas relações sociais, que é justamente o papel de conduzir os indivíduos no processo de apropriação das objetivações genéricas para-si. (DUARTE, 1999, p. 40).

É essa mediação entre a vida cotidiana e suas objetivações em-si e a atividade nãocotidiana e suas objetivações para-si que humaniza a vida humana e que traz a possibilidade de uma transformação nas relações sociais ao contribuir para que o homem tenha acesso às objetivações construídas historicamente.

A mediação entre os conhecimentos espontâneos da vida cotidiana dos(as) alunos(as) e os conhecimentos científicos construídos historicamente é o fator determinante que estimula o desenvolvimento da criança em fase escolar, pois, ao se relacionar conscientemente com o âmbito do não-cotidiano a partir dos conhecimentos científicos, o(a) aluno(a) se educa para não se reduzir a uma criatividade repetitiva e pragmática, mas relativamente se distanciar do imediatismo da vida cotidiana e a ela retornar teoricamente em níveis mais elevados. Vale salientar que, embora a ciência faça parte do âmbito da vida não-cotidiana, não tem como dissociá-la da vida cotidiana, visto que se pode utilizar da ciência de forma pragmática para realizar atividades do dia a dia.

\footnotetext{
A escola não visa apenas a essa utilização pragmática de produtos da ciência. Ela visa a que o indivíduo possa fundamentar na ciência o pensamento e a ação em vários momentos da vida social. São momentos nos quais o indivíduo supera (ainda que parcialmente) a heterogeneidade e o pragmatismo da vida cotidiana e se dirige por uma relação homogênea com a ciência. Quando um indivíduo utiliza conhecimentos históricos para buscar compreender sua situação como membro da classe social, está ultrapassando (tendencialmente) a consciência de classe em-si e está buscando a consciência de classe para-si (DUARTE, 1999, p. 64).
}

As atividades do homem que são conduzidas a partir da apropriação das objetivações genéricas para-si têm como propriedades particulares a mediação dos instrumentos construídos socio-historicamente pelo homem, portanto, são esses instrumentos que permeiam o homem e o produto de sua ação. Desse modo, o papel do(a) professor(a), como mediador(a) do conhecimento, através da utilização dos instrumentos culturais e psicológicos e da prática social do(a) aluno(a), é fundamental para que o(a) discente se aproprie dos conhecimentos e que os convertam em instrumentos de transformação social.

A partir do exposto acerca do que seja o processo de mediação na escola, podemos afirmar que, para Vigotski, a mediação ocorre através dos elementos e conhecimentos construídos historicamente pelo homem e é indispensável para o(a) aluno(a)para o qual seja oportunizado o acesso a essas construções históricas, uma vez que é, a partir delas, que o humano se humaniza. 


\section{iff: tear}

Revista de Educação, Ciência e Tecnologia

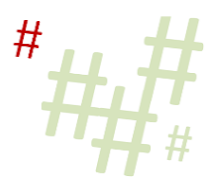

\section{0 desenvolvimento das funções psicológicas}

De acordo com Vigotski (1991), o desenvolvimento das funções psicológicas ocorre pela aquisição/aprendizagem de tudo aquilo que o indivíduo constrói socialmente ao longo da história da humanidade e, nesse processo de mediação, o(a) professor(a) é a representação do conhecimento em seu fazer pedagógico.

A transmissão desse conhecimento se dá de forma intencionalmente elaborada para possibilitar o desenvolvimento e a inserção do(a) aluno(a) em um conhecimento construído histórica e coletivamente pelos homens.

As funções psicológicas superiores são formadas nas relações sócio-históricas, porém nascemos com funções elementares que são fundamentais no desenvolvimento das funções superiores, ou seja, elas não se desenvolvem do nada, mas se originam das relações sociais que são dinâmicas, contraditórias e nas quais o homem se insere, portanto, dialéticas. Ao construir uma relação com o meio a partir de sua atividade, o homem desenvolve sua estrutura cognitiva e modifica a realidade

A partir do exposto, entendemos que a atividade humana pode ser observada sob a ótica de duas perspectivas. A primeira é aquela em que a atividade humana reproduz o que já foi construído como forma de conservar a formação cultural, instalando uma constante manutenção cultural. O segundo entendimento é aquele em que, a partir da cultura conservada o homem age sobre ela, transformando-a, não se esquecendo do que ela já foi, porque é essencial ter em mente a origem do conhecimento, saber de onde partiu, mas tendo em vista que embora esse conhecimento tenha sido transformado, ele é passível de mais transformações a partir da concepção de quem realiza atividade.

Para a psicologia histórico-cultural, é a partir da imitação que se desenvolvem as propriedades da consciência que são inerentes ao ser humano porque, para imitar, o homem precisa compreender o significado da ação que ele quer imitar, logo, não é uma simples ação mecânica sem compreensão. É a partir dessa consciência do significado da ação do outro que consiste a diferença entre o homem e o animal, visto que o animal não é passível de evoluir através desse processo de imitação. Quando ensinamos a um animal temos que considerar que o conceito de ensino não é o mesmo pensado para o ser humano.

\footnotetext{
Reside aí a grande diferença entre a imitação humana e animal. Na imitação propriamente humana, a conduta a ser imitada precisa ser em alguma medida compreendida pela criança, ou seja, a imitação só é possível se acompanhada do entendimento. Por isso, nem tudo pode ser imitado pela criança: “a criança só consegue imitar o que se encontra na zona das suas próprias potencialidades intelectuais". (MARTINS; DUARTE, 2010, p.175).
}

É no processo dialético do homem com a natureza que ele constrói novos comportamentos e processos psicológicos, consequentemente, as funções psicológicas humanas são elaboradas a partir de suas relações com o meio. Essas funções na infância se apresentam no contato com outras crianças, na convivência com adultos e na relação com o(a) professor(a) e, no futuro, as crianças incorporam o seu comportamento e a sua concepção de mundo.

Se as funções psicológicas superiores se desenvolvem por meio da apropriação da cultura, há necessidade daquele que tem domínio do patrimônio humano-genérico para transmitir às novas gerações aquilo que o desenvolvimento humano lhes garantiu 


\section{iff: tear}

Revista de Educação, Ciência e Tecnologia

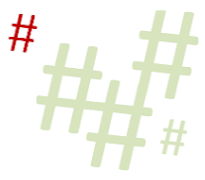

ao longo de sua história, produzindo desenvolvimento psicológico fundamental ao sujeito e sua constituição psicofísica. (MARTINS; DUARTE, 2010, p. 107).

Pode-se afirmar, a partir do exposto, que, de acordo com a psicologia histórico-cultural, o desenvolvimento das funções psicológicas não são apenas resultados da biologia, mas são desenvolvidas fundamentalmente a partir das relações socioculturais. São as transformações por que passa o homem, as influências das relações sociais e o meio no qual está inserido o principal fomento para o desenvolvimento cultural.

\section{A formação dos conceitos na idade escolar}

O conceito é uma construção e, à medida que o ser humano vai se tornando consciente dos conceitos, vai organizando os pensamentos conscientizados para-si.

$\mathrm{Na}$ perspectiva da psicologia histórico-cultural, a formação dos conceitos diverge do caminho apresentado pelo construtivismo piagetiano, visto que esses conceitos são desenvolvidos a partir das circunstâncias sociais, do contexto histórico-cultural, no qual está inserida a criança. Portanto, apesar de a escola ter um papel fundamental na formação dos conceitos, esse processo não depende apenas do conhecimento que o(a) professor(a) ensina, mas de todo o contexto em que a criança está inserida.

A dialética marxista, na concepção de Vigotski, apresenta-se na reflexão sobre o que seja o conceito e de como esses conceitos estão interligados e se comunicam, ou seja, apesar dos conceitos espontâneos e científicos apresentarem características diferentes e suas vias ocorrerem de forma diferente, um necessita do outro para que se desenvolvam.

Para a psicologia histórico-cultural, o conceito científico necessita de um desenvolvimento anterior dos conceitos espontâneos no processo de formação dos conceitos. A questão da relação conceitos espontâneos e científicos, para Vigotski, se insere, de forma imbricada, na problemática da relação processo de ensino e aprendizagem.

Para o desenvolvimento do conceito científico, em determinada idade escolar, é necessário que os conceitos espontâneos tenham alcançado certo grau de desenvolvimento, ou seja, tenham atingido certa maturidade através da colaboração permanente do ser humano adulto ou de crianças mais velhas. Enquanto o conceito espontâneo é concebido na espontaneidade do cotidiano, o conceito científico depende da aprendizagem escolar, de forma que a criança veja a essência no que antes via apenas a aparência.

Logo, os conceitos científicos, ao serem ensinados na escola, reconstroem os conceitos espontâneos que são adquiridos no cotidiano, entretanto, para que esse processo ocorra faz-se necessário o desenvolvimento prévio dos conhecimentos espontâneos adquiridos no cotidiano, para que, a partir da mediação do(a) professor(a), aconteça o desenvolvimento das funções psicológicas superiores do(a) aluno(a) e a promoção do desenvolvimento cultural, ou seja, o(a) aluno(a), para se desenvolver culturalmente, necessita da ação do(a) professor(a). Ou seja, é a partir da colaboração do(a) professor(a) que os conceitos científicos, organizados por princípios e leis, serão apropriados pelo(a) aluno(a).

No fundo, o problema dos conceitos não-espontâneos e, particularmente, dos conceitos científicos é uma questão de ensino e desenvolvimento, uma vez que os conceitos espontâneos tornam possível o próprio fato do surgimento desses conceitos a partir da aprendizagem, que é a fonte do seu desenvolvimento. Por isso o problema 


\section{iff: tear}

Revista de Educação, Ciência e Tecnologia
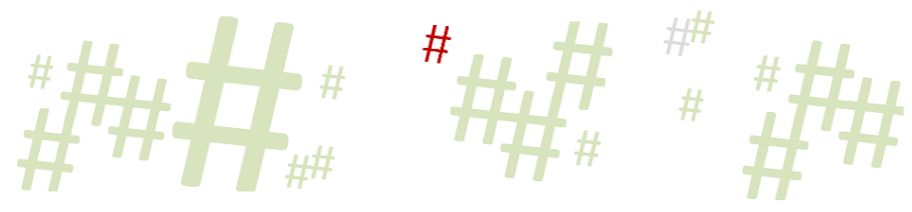

dos conceitos espontâneos e não-espontâneos é um caso particular de um estudo mais geral da questão da aprendizagem e do desenvolvimento. (VIGOTSKI, 2009, p. 296).

Nesse sentido, Vigotski (2009, p. 260) trabalha com a relação dialética entre os dois conceitos: o espontâneo e o científico. O conceito espontâneo é o conhecimento não sistematizado, espontâneo, previamente trazido pelo(a) aluno(a) e o científico é o conhecimento sistematizado a ser apreendido na escola, embora seu desenvolvimento dependa da transformação dos conhecimentos espontâneos. Quando o conhecimento espontâneo não ascende a um conhecimento mais elaborado, através do acesso ao conhecimento científico, entende-se que não houve mudança qualitativa desse saber. Portanto, a falta desse salto qualitativo influencia diretamente a construção de sujeitos capazes de analisar criticamente a realidade sócio-histórica em que se encontra inserido e contribuir para a sua transformação, ou seja, é se apropriando dos conceitos científicos que ocorre a elevação cultural e se superam os conceitos espontâneos.

\footnotetext{
Do ponto de vista dialético, os conceitos não são conceitos propriamente ditos na forma como se encontram no nosso discurso cotidiano. São antes noções gerais sobre as coisas. Entretanto, não resta nenhuma dúvida de que representam um estágio transitório entre os complexos e pseudoconceitos e os verdadeiros conceitos no sentido dialético desta palavra. (VIGOTSKI, 2009, p. 218).
}

Para a psicologia histórico-cultural, a formação dos conceitos ocorre no decorrer de três estágios que se subdividem em várias fases. O primeiro estágio é chamado de "formação da imagem sincrética ou amontoado de objetos"; o segundo, de "pensamento por complexos" e o terceiro, de "abstração, conceitos potenciais e verdadeiros conceitos". Neste ponto, devemos assinalar que não há sequência em Vigotski, essas fases podem se repetir a partir do contato com o novo que aciona todo um novo processo de aprendizagem.

O primeiro estágio ocorre logo no início da vida do ser humano, no qual se constroem imagens sincréticas.

Nesse estágio do desenvolvimento, o significado da palavra é um encadeamento sincrético não enformado de objetos particulares que, nas representações e na percepção da criança, estão mais ou menos concatenados em uma imagem mista. Na formação dessa imagem cabe o papel decisivo ao sincretismo da percepção ou da ação infantil, razão por que essa imagem é sumamente instável. (VIGOTSKI, 2009, p. 175).

Esse estágio é subdividido em três fases: "provas e erros", "encontros espaciais e temporais"e "equivalência do sincrético ao conceito". Ao longo desse estágio, conforme sinaliza Vigotski (2009, p. 176), a criança começa a perceber as diferenças nos objetos identificando que há elementos de um grupo, que não estão presentes no outro grupo e, por fim,a criança não junta as coleções por atributos, mas por significados.

[...] cada um dos elementos particulares da nova série sincrética ou amontoado é o representante de algum grupo de objetos anteriormente unificado na percepção da criança, mas todos esses elementos juntos não guardam nenhuma relação interna entre si e representam o mesmo nexo desconexo do amontoado que os equivalentes dos conceitos nas duas fases antecedentes. (VIGOTSKI, 2009, p. 177). 


\section{iff: tear}

Revista de Educação, Ciência e Tecnologia
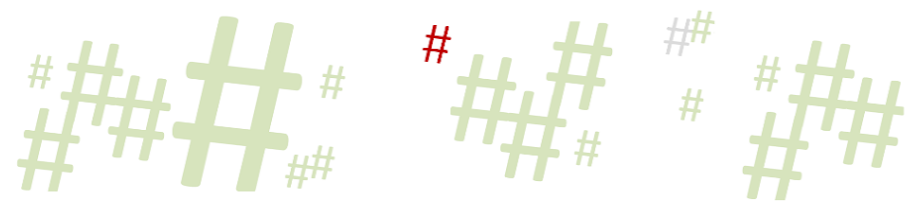

No segundo estágio, o de pensamentos por complexos, a criança passa a construir vínculos, mesmo que de forma rudimentar. Nesse estágio, a criança não mais confunde as relações das coleções.

O pensamento por complexos já constitui um pensamento coerente e objetivo. Estamos diante de dois novos traços essenciais, que o colocam bem acima do estágio anterior, mas ao mesmo tempo, essa coerência e essa objetividade ainda não são aquela coerência característica do pensamento conceitual que o adolescente atinge. (VIGOTSKI, 2009, p. 179).

O estágio de pensamentos por complexos se subdivide em cinco fases. A primeira fase é chamada de complexo de "tipo associativo", porque o indivíduo nessa fase tem o vínculo como essencial. O complexo ainda é fortuito e factual ligado ao fazer relação de objetos porque para a criança é algo parecido ou semelhante. A segunda fase, a das "coleções", os vínculos são estabelecidos, mesmo que não vejam os objetos. Aqui se dá a organização de objetos por cores, formas, tamanhos, tendo assim uma associação por contraste, estabelecidos na experiência prática da criança e não em emoções e subjetividades. A fase do "complexo em cadeias" é a terceira fase e, conforme Vigotski (2009, p. 185), é a fase em que o pensamento por complexos pode ser considerado puro. Para Vigotski, esses estágios e fases não são vistos como o momento da construção do conhecimento, mas de desenvolvimento de conceitos. A quarta fase é denominada de "complexo difuso" porque é o momento que começa a ocorrer a abstração, mas a criança ainda não sabe como explicar o seu pensamento, o porquê da ação. Aqui ocorre um avanço conceitual, porque o vínculo se perde, ocorreu à abstração, mas não se manteve porque não teve consistência, daí decorre a dificuldade da criança de explicar o que fez e como fez.

[...] o análogo natural do complexo difuso no desenvolvimento do pensamento da criança são as generalizações que a criança produz precisamente naqueles campos do seu pensamento que não se prestam a uma verificação prática, noutros termos, nos campos do pensamento não-concreto e não-prático. (VIGOTSKI, 2009, p. 189).

A quinta fase do pensamento por complexos é denominada "pseudoconceito", porque, para Vigotski (2009, p.190), "em termos externos, temos um conceito, em termos internos, um complexo", ou seja, nesta fase a criança se encontra no limiar de uma etapa para outra e ainda que tenha laços com o conceito, ela ainda está difusa, está nos complexos. É a fase em que os pensamentos das crianças se assemelham ao dos adultos, mas se difere na essência do seu pensamento. Para o autor, "Os pseudoconceitos constituem a forma mais disseminada, predominante sobre todas as demais e frequentemente quase exclusiva do pensamento por complexos na idade pré-escolar" (VIGOTSKI, 2009, p. 191).

A criança não relaciona espontaneamente uma dada palavra a um determinado grupo concreto e transfere o seu significado de um objeto para outro, ampliando o círculo de objetos abrangidos pelo complexo. Ela apenas segue o discurso dos adultos, assimilando os significados concretos das palavras já estabelecidos e dados a ela em forma pronta. Em termos mais simples, a criança não cria a sua linguagem, mas assimila a linguagem pronta dos adultos que a rodeiam. Isto diz tudo. E compreende também o fato de que a criança não cria por si mesma complexos correspondentes ao significado da palavra, mas os encontra prontos, classificados com o auxílio de palavras e denominações comuns. Graças a isto, os seus complexos coincidem com os conceitos dos adultos e surge o pseudoconceito - o conceito-complexo. (VIGOTSKI, 2009, p. 196).

\# Tear: Revista de Educação Ciência e Tecnologia, v.10, n.2, 2021. 


\title{
iff: tear
}

Revista de Educação, Ciência e Tecnologia
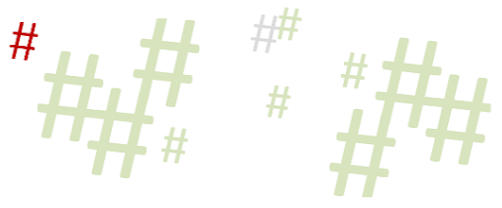

O terceiro e último estágio da evolução do pensamento infantil é subdividido em três fases e é denominado como o estágio das abstrações dos conceitos potenciais e dos conceitos verdadeiros, não ocorrendo necessariamente nessa ordem. Para Vigotski (2009), não há separação entre o pensar e a realidade. $\mathrm{O}$ símbolo, o significado e o significante devem ser vistos de forma indissociáveis.

Na fase da "abstração", as relações não são feitas no concreto, mas no abstrato, tendo como característica principal a oscilação do pensamento. Para Vigotski (2009, p. 226), "só o domínio do processo da abstração, acompanhado do desenvolvimento do pensamento por complexos, pode levar a criança a formar conceitos de verdade". Os "conceitos potenciais", característicos da segunda fase, conforme o autor, ainda não são propriamente um conceito, mas podem se desenvolver e alcançar esse status.

\begin{abstract}
É verdade que uma característica do pensamento puramente por complexos é o fato de ele ser extremamente instável, ceder seu lugar a outro atributo e não ser de forma alguma um atributo privilegiado em comparação com todos os demais. Não é o que ocorre com o pensamento potencial. Aqui, o atributo que serve de base à inclusão do objeto em um grupo comum é um atributo privilegiado, abstraído do grupo concreto de atributos aos quais está efetivamente vinculado. [...] Lembremos que na história das nossas palavras esses conceitos potenciais desempenham papel de suma importância. Citamos muitos exemplos de como toda palavra nova surge com base na discriminação de algum atributo evidente e serve de base à construção da generalização de vários objetos nomeados ou representados por uma mesma palavra. Esses conceitos potenciais assim permanecem em dada fase do seu desenvolvimento, sem se transformar em um verdadeiro conceito (VIGOTSKI, 2009, p. 225).
\end{abstract}

Por fim, a fase dos "verdadeiros conceitos" tem como particularidade o pensar sobre os próprios pensamentos. Assim, o desenvolvimento da consciência, o início da construção das formações superiores, somente chegará ao seu ápice, ou seja, ao pensamento conscientizado, ao pensamento por conceitos, na adolescência. O conhecimento científico possibilita ao homem pensar por conceitos e realizar as abstrações sobre o pensamento. Mas os próprios conceitos do adolescente e do adulto, uma vez que sua aplicação se restringe ao campo da vivência puramente cotidiana, frequentemente estão no nível dos pseudoconceitos e, mesmo tendo todos os atributos de conceitos do ponto de vista da lógica formal, ainda assim não são conceitos do ponto de vista da lógica dialética e não passam de complexos.

Toda formação e domínio dos conceitos está na ZDP. Assim, enquanto na relação conceito espontâneo e científico, o conceito científico somente pode agir sobre o espontâneo, conquanto que este último tenha atingido certo grau de maturidade, essa relação também somente pode vir a ocorrer a partir da ação, da colaboração permanente do professor, como ser humano adulto, de forma que os conceitos científicos, organizados por princípios e leis, sejam assentados.

\section{A concepção docente acerca da mediação}

Para compreender a concepção do(a) professor(a)acerca da mediação pedagógica, partimos do princípio de que a concepção desses sujeitos é construída sócio-historicamente a partir das reproduções e contradições que são inerentes à construção social. Logo, a partir do 


\section{iff: tear}

Revista de Educação, Ciência e Tecnologia

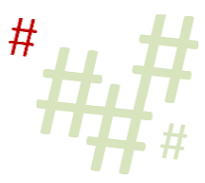

momento em que o(a) professor(a) adquire consciência das contradições sociais, através de outras mediações do conhecimento, também se torna um(a) mediador(a) dessa consciência.

Tendo essa compreensão e compactuando com uma visão dialética histórica, analisamos as informações coletadas com oito professoras de escolas do ensino fundamental através de entrevistas semi-estruturadas, buscando destacar as particularidades da mediação na concepção dos sujeitos entrevistados. Com o intuito de preservar a identidade dos sujeitos que se dispuseram a participar da pesquisa ${ }^{4}$, estabeleceu-se o anonimato dos sujeitos, identificando-os numericamente de um a oito.

A respeito da mediação, das oito professoras entrevistadas, quatro destacam que o papel do(a) professor(a) é o de ser o(a) mediador(a) do conhecimento, a partir de ferramentas às quais as crianças não têm acesso e por meio de atividades previamente organizadas. Nessa perspectiva, a relação do(a) aluno(a) com o meio escolar é mediada por um outro indivíduo, o(a)docente, que é responsável por se apropriar de conhecimentos que foram historicamente construídos.

Nesse sentido, as professoras 2 (dois) e 8 (oito) descrevem, respectivamente, o papel do(a) professor(a) em sala de aula, como: "o papel do professor é de mediador. Eu trago as ferramentas que na maioria das vezes os alunos não têm acesso"; "professor é o mediador porque você lida com essas crianças e temos que fazer essa mediação do conhecimento"; "o papel do professor é de peça fundamental, ele é o mediador do conhecimento, ele é a pessoa preparada e sabe como trabalhar para tirar o melhor do aluno". Por sua vez, a professora 7 (sete) acrescenta que o trabalho do professor é:

[...] favorecer a aprendizagem, o pensamento, fazer com que os alunos façam novas descobertas não de forma livre, mas escolher atividades que alcancem o objetivo que foi planejado através de atividades. O papel do professor é ser realmente mediador, ele está ali porque tem conhecimentos para planejar atividades que faça com que o aluno rompa com o que já sabe e criar desafios para que ele aprenda coisas novas.

$\mathrm{O}(\mathrm{A})$ professor(a), numa perspectiva vigotskiana, é o indivíduo conhecedor das relações sociais que medeiam os instrumentos materiais e intelectuais de forma a favorecer $o$ desenvolvimento da criança, não se esquecendo da ZDP e do NDA, de forma que haja um efetivo desenvolvimento das funções superiores de seu discente.

Para Marsiglia (2011, p. 36), "o educador, como um parceiro mais experiente, é aquele que faz a mediação da criança com o mundo de forma "intencional", buscando as máximas possibilidades de desenvolvimento do indivíduo" [grifo do autor].

Por outro lado, a professora 1(um) compreende o papel do(a) professor(a) como aquele que "molda esse ser humano do futuro, para ser profissional", apresentando uma perspectiva pedagógica tecnicista em que o(a) professor(a) é o sujeito responsável por executar técnicas e procedimentos que preparam o(a) aluno(a) como indivíduo flexível e adaptável para atender às exigências do mercado de trabalho. Esse papel técnico do(a) professor(a), embora atenda a uma necessidade do indivíduo de suprir às necessidades objetivas, imediatas, que são inerentes à sua

\footnotetext{
${ }^{4}$ Esta pesquisa foi aprovada pelo Comitê de Ética em Pesquisa (CEP) da Universidade Federal da Paraíba, conforme os termos da Resolução no . 466/2012 e 510/2016 do Conselho Nacional de Saúde (Parecer nº 3.293.810, de 30 de abril de 2019).
} 


\section{iff: tear}

Revista de Educação, Ciência e Tecnologia

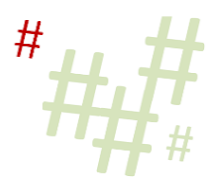

própria subsistência, torna-se contraditória ao secundarizar o acesso do(a) aluno(a) ao conhecimento elaborado historicamente, reproduzindo as relações de produção ao assentir com o modo de pensar dos que detêm o capital.

A função de mediar os conhecimentos historicamente construídos não pode ser minimizada como papel inerente ao professor(a) e à escola, visto que,segundo Saviani (2013, p. 20), "a restrição do acesso à cultura erudita conferirá àqueles que dela se apropriam uma situação de privilégio, uma vez que o aspecto popular não lhes é estranho", aumentando o abismo gestado na divisão do trabalho,através de práticas pedagógicas excludentes.

Nessa perspectiva, Martins e Duarte (2010, p. 143) vêm a contradição na escola em que "se manifesta a luta entre o caráter humanizante da transmissão às novas gerações das obras mais ricas do conhecimento humano e o caráter alienante da reprodução da ideologia burguesa", reforçando a dicotomia do papel do(a) professor(a) na sociedade.

Por sua vez, a professora 4 (quatro) compreende seu papel como "encaminhar a criança ao objetivo que foi definido no planejamento de aula" e acrescenta que o(a) professor(a) "é a segurança, o porto seguro da criança nesse processo de aprendizagem. A criança sempre vai procurar o professor porque a gente está dando subsídio, tirando dúvidas". Nessa concepção, pode-se observar a descaracterização do papel do(a) professor(a) como aquele que, apesar de deter um saber a ser transmitido, está ali para encaminhar e tirar dúvidas, minimizando o papel do(a) professor(a) como um protagonista secundário do fazer pedagógico, negando o próprio ato de ensinar e exaltando que o(a) aluno(a) aprenda a aprender, perspectiva essa comungada pelo escolanovismo e abordagens neoliberais e pós-modernas que, segundo Marsiglia (2011, p. 15), "pensam a escola como espaço de negociação de significados e conteúdos e não como espaço de transmissão-assimilação de conhecimento".

A não compreensão de que a prática do(a) professor(a) é também uma prática social, portanto, sujeita às mudanças que ocorrem na sociedade, termina por reduzir o papel do professor(a) a um fazer pedagógico que reproduz as estruturas sociais que estão postas. Por outro lado, a compreensão acerca do papel histórico do(a) professor(a) no processo de ensinoaprendizagem, concebida como prática social, representa, em última instância, a possibilidade de transformação da própria realidade social em que professores(as) e alunos(as) estão inseridos, uma vez que o seu fazer pedagógico estará voltado para a apropriação do conteúdo pelo aluno, transformando-o de conteúdo em-si em conteúdo para-si.

No decorrer da pesquisa, embora as professoras entrevistadas tivessem apontado o(a)professor(a) como mediador(a) no processo de ensino-aprendizagem, a concepção acerca do conceito mediação apresenta fragilidades teóricas.

A professora 1 (um) situa a mediação como um processo de construção, no qual "você vai construindo o conhecimento do aluno, [...]você pega o que ele já sabe e vai moldando, vai desfazendo os mitos e transformando os mitos em conhecimento científico".

Para a professora 2 (dois), a mediação aparece como um elo "[...] eu estou ali para fazer a criança chegar a um conhecimento mais elaborado. Então eu me vejo como essa ligação. Eles têm um conhecimento e eu posso ajudar, estimular e fazer com que aquilo se transforme em um outro conhecimento".

A professora 5 (cinco) apresenta a mediação como "conciliação do aprender e do ensinar. [...] o professor tem que mediar o que vai ensinar porque é exigido vários conteúdos, então naquele conteúdo você vai ter que ser o mediador". 


\section{iff: tear}

Revista de Educação, Ciência e Tecnologia

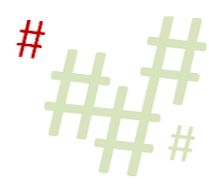

Vale destacar a fala da professora 7 (sete) que aponta o processo de mediação como ponte. A professora sinaliza que, durante sua graduação e pós-graduação, "se discutia muito sobre o papel do professor como mediador, não como um simples transmissor de conhecimento, mas como uma ponte que ajuda a criança a construir conhecimento".

A indefinição teórica acerca do conceito de mediação docente denotam, primeiro as inconsistências e fragilidades teórico-práticas na formação dos profissionais e, segundo, uma impossibilidade de compreensão acerca do fazer pedagógico enquanto prática social intencional.A teoria e a prática são faces de uma mesma moeda, elas são intrínsecas. A teoria não se constrói sem a prática e a transformação da prática não se dá sem a teoria, sem a reflexão. Para Vásquez (2011, p. 210), não se separa a atividade do homem, da natureza: "Não se pode separar uma forma da outra, [...] os fins do homem em relação aos quais a atividade prática e o mundo objetivo são orientados".

\section{Considerações finais}

A concepção da psicologia histórico-cultural sobre a educação escolar é a de que o fazer pedagógico não se reduz às atividades cotidianas da realidade escolar, mas é uma ação mediadora da formação do aluno com sua cotidianidade e suas relações. É a mediação do cotidiano com o não-cotidiano que podem trazer a superação da aparência do cotidiano, a humanização da vida humana e a possibilidade de transformação nas relações sociais

Nesse sentido, é imprescindível que haja uma mudança estrutural na formação do professor visando situar a importância da teoria na prática pedagógica e a consciência de que toda atividade humana é dirigida a um determinado fim, cabendo ao autor da atividade refletir a que fim está sendo orientada a sua prática, se para a transformação ou para a reprodução social.

O papel do(a) professor(a)como aquele(a) que possibilita a constituição de um sujeito historicamente situado a partir do acesso ao conhecimento acumulado pela humanidade vem sendo secundarizado pela ideia equivocada de que o aluno pode ser ativo e responsável pela sua própria aprendizagem, esvaziando o ensino e empobrecendo o trabalho do professor tido como o mediador do conhecimento historicamente acumulado.

\section{Referências}

CURY, C. R. J. Educação e contradição: Elementos metodológicos para uma teoria crítica do fenômeno educativo. São Paulo: Autores associados, 1986.

DUARTE, N. Educação escolar, teoria do cotidiano e a escola de Vigotski. 2. ed. Campinas-SP: Autores Associados, 1999.

DUARTE, N. Vigotski e o aprender a aprender: Críticas às apropriações neoliberais e pósmodernas da teoria vigotskiana. Campinas-SP: Autores Associados, 2003.

HELLER, A. O cotidiano e a história.São Paulo: Editora Paz e Terra, 1992.

\section{MARSIGLIA, A. C. G. A prática pedagógica histórico-crítica na educação infantil e} ensino fundamental. Campinas -SP: Autores Associados, 2011. 
MARTINS, L.M.; DUARTE, N. (org.). Formação de professores: Limites contemporâneos e alternativas necessárias [online]. São Paulo: UNESP, 2010.

OLIVEIRA, B.A; DUARTE, N. Socialização do saber escolar. São Paulo: Cortez: Autores Associados, 1985.

PRESTES, Z.R. Quando não é quase a mesma coisa: Análise de traduções de Lev Semionovitch Vigotski no Brasil,repercussões no campo educacional. 2010. 294f. Tese (Doutorado) - Universidade de Brasília, Faculdade de educação, Brasília, DF, 2010. Disponível em: https://repositorio.unb.br/handle/10482/9123. Acesso em: 20 ago. 2019.

SAVIANI, D. Pedagogia histórico-crítica: Primeiras aproximações. Campinas-SP: Autores Associados, 2013.

VÁSQUEZ, A. S. Filosofia da práxis. 2. ed. São Paulo: Expressão Popular, 2011.

VIGOTSKI, L.S. A formação social da mente. 4. ed. São Paulo: Martins Fontes, 1991.

VIGOTSKI, L. S. A construção do pensamento e da linguagem. 2. ed. São Paulo: Editora WMF Martins Fontes, 2009.

Recebido em agosto de 2021.

Aprovado em outubro de 2021. 